\title{
Radiolabeling Chemistry with Heavy Halogens lodine and Astatine
}

\author{
Romain Eychenne ${ }^{a, b}$, Cyrille Alliot $^{b}$, Jean-François Gestin ${ }^{a}$ and François Guérard ${ }^{a}$ \\ a Université de Nantes, CNRS, Inserm, CRCINA, F-44000 Nantes, France \\ ${ }^{\mathrm{b}}$ Arronax GIP, Saint-Herblain, France
}

\section{François Guérard, PhD (Corresponding author)}

Institut de Recherche en Santé de l'Université de Nantes

Centre de Recherche en Cancérologie et Immunologie de Nantes-Angers (CRCINA)

UMR 1232 Inserm - ERL 6001 CNRS

Equipe 13 (Recherche en Oncologie Nucléaire)

8 Quai Moncousu

44007 Nantes Cedex 1- France

francois.guerard@univ-nantes.fr

Phone + 33228080295

\section{Romain Eychenne, PhD}

Arronax GIP

1 Rue Aronnax

44800 Saint-Herblain - France

romain.eychenne@univ-nantes.fr

Phone + 33228080220

Cyrille Alliot, PhD

Arronax GIP

1 Rue Aronnax

44800 Saint-Herblain - France

alliot@arronax-nantes.fr

Phone + 33228212524

\section{Jean-François Gestin, PhD}

Institut de Recherche en Santé de l'Université de Nantes

Centre de Recherche en Cancérologie et Immunologie de Nantes-Angers (CRCINA)

UMR 1232 Inserm - ERL 6001 CNRS

Equipe 13 (Recherche en Oncologie Nucléaire)

8 Quai Moncousu

44007 Nantes Cedex 1- France

jean-francois.gestin@univ-nantes.fr

Phone + 33228080221 


\begin{abstract}
lodine and astatine radioisotopes are particularly attractive in nuclear medicine since their available isotopes cover all imaging and therapeutic modalities, from SPECT and PET imaging to beta, alpha and Auger electron therapy. Furthermore, their radiolabeling chemistry is highly versatile, being mainly based on covalent chemistry, unlike most other radionuclides that are metals. This makes them easily adaptable for the radiolabeling of a broad range of carrier compounds, from small molecules to large proteins. lodine and astatine being both neighboring halogens, their radiolabeling chemistry is very similar. Knowledge on At is however limited given its low availability over the past decades and the facts that it exists only as short-lived isotopes, which has long hampered the study of its chemical properties. Nonetheless, recent research has highlighted features that distinguish it from its lighter halogen homologues and late developments open new perspectives with astatine radioisotopes to produce radiopharmaceuticals.

In this chapter, the basics of iodine and astatine labeling chemistry are covered in parallel, starting with general principles and then detailing more specific applications and issue. In a first part the main production methods for the most relevant radionuclides, and the corresponding chemicals forms available for radiolabeling chemistry are presented. Radiolabeling reactions, which can be classified as electrophilic or nucleophilic, are introduced and their advantages and drawbacks are discussed. The second part introduces issues encountered in the specific case of proteins radiolabeling and the main strategies available. Finally, a third part discusses the stability issues encountered with iodine and especially At-labeled radiopharmaceuticals and the main approaches under investigation to improve it. The perspectives sections discuss the potential of iodine and astatine radioisotopes in the context of the development of the radiotheranostic modality.
\end{abstract}

Key Words : radioiodine, astatine, radiohalogenation, bioconjugates, protein labeling, stability

\title{
Introduction
}

lodine and astatine radioisotopes are very attractive for nuclear medicine applications since they can be used for all imaging and therapeutic modalities through their main isotopes of interest: ${ }^{123}{ }^{1}\left(t_{1 / 2}=\right.$ $13.2 \mathrm{~h}$ ) for SPECT imaging, ${ }^{124} \mathrm{I}\left(\mathrm{t}_{1 / 2}=4.18\right.$ days) for PET imaging, ${ }^{125} \mathrm{I}\left(\mathrm{t}_{1 / 2}=59.9\right.$ days) for Auger electron therapy, ${ }^{131} \mathrm{I}\left(\mathrm{t}_{1 / 2}=8\right.$ days) for $\beta^{-}$-therapy, and ${ }^{211} A t\left(t_{1 / 2}=7,2 \mathrm{~h}\right)$ for $\alpha$-therapy. Being both halogens, the heaviest in the series, they exhibit the advantage over other medical radionuclides, which are mainly metals, to be attached to the carrier molecules by forming covalent bonds. This limits the modification of initial molecules, lowering the risk of altering their in vivo pharmacokinetics in comparison with often large and charged chelating agents required for labeling with radiometals. Radioiodine labeling strategies have been developed based on chemical concepts already known in conventional synthetic chemistry with iodine or lighter halogens, and some of the most efficient reactions to form carbon-iodine bonds have been adapted to the constraints of radiolabeling chemistry, that are mainly : i) the work in small volumes and high dilution, ii) the simplicity of application in a radioprotective setting, and iii) the rapidity of the reaction and subsequent purification, especially for short half-life isotopes. On the other hand, astatine do not exhibit stable isotopes, only short half-life isotopes ( $\leq 8.1 \mathrm{~h}$ ) being known and present on Earth as traces. Available only in tiny amounts and extremely low concentration, this element is invisible to conventional spectroscopic tools to study it. This has impaired the development of knowledge on this 
radioelement since its discovery in the 1930 s, when ${ }^{211}$ At was produced artificially with a cyclotron for the first time. Astatines chemical behavior is, however, very similar to iodine in the context of radiolabeling chemistry, and despite a marked metallic character observed under specific conditions, radioiodination procedures are in the majority of cases applicable to this radioelement and a number of relevant astatinated radiopharmaceuticals have been prepared for therapeutic applications. However, the lower labeling stability is an issue that remains to be resolved to expand its scope of application.

The radiolabeling strategy employed depends on the substrate to be labeled, but also on the starting radionuclide species available (which oxidation state and in which medium) that is in turn governed by its mode of production as detailed in the following subsections.

\section{I - General considerations on the production of radioiodinated and astatinated compounds}

\section{I.I. Production of main iodine and astatine radioisotopes}

\section{I.I.I lodine-123, iodine-124, iodine-125 and iodine-131.}

${ }^{123} \mathrm{I}$ and ${ }^{125} \mathrm{I}$ are mainly produced from enriched xenon targets whereas ${ }^{124} \mathrm{I}$ and ${ }^{131} \mathrm{I}$ are generally obtained from tellurium targets. ${ }^{123} \mathrm{I}$ is routinely produced commercially from ${ }^{123} \mathrm{Xe}$ decay $\left(\mathrm{t}_{1 / 2}=2.1\right.$ h) obtained by proton irradiation of ${ }^{124} \mathrm{Xe}$ trapped in a capsule (Firouzbakht et al., 1987). The proton energy must be controlled between 15 and $34 \mathrm{MeV}$ to keep ${ }^{125}$ I contamination below the detection limits. The advantage of this indirect production route is that it allows the separation of Xe from initial target, limiting contamination from others iodine radioisotopes. An alternative production route uses ${ }^{123} \mathrm{Te}$ target bombarded by protons (Mahunka et al., 1996). This route, that requires small medical cyclotron broadly found in medical and research centers for routine ${ }^{18} \mathrm{~F}$ or ${ }^{11} \mathrm{C}$ production, makes this nuclide easily available, but ${ }^{124} \mathrm{I}$ impurities are unavoidable. ${ }^{125} \mathrm{I}$ is produced from ${ }^{125} \mathrm{Xe}\left(\mathrm{t}_{1 / 2}\right.$ $=57 \mathrm{~s}$ ) that is itself obtained via the neutron irradiation of ${ }^{124} \mathrm{Xe}$ in nuclear reactors. The production process must however be carefully controlled because of potential ${ }^{126}$ I contamination $\left(t_{1 / 2}=13.1 \mathrm{~d}\right.$ ) due to neutron capture of ${ }^{125}$ I (Martinho et al., 1984).

The main ${ }^{124} \mathrm{I}$ production approach is by proton irradiation of ${ }^{124} \mathrm{Te}$ with a beam energy $\leq 17 \mathrm{MeV}$, making it available from small medical cyclotron (Qaim et al., 2003). ${ }^{131} \mathrm{I}$ is in majority produced as a decay product of ${ }^{131} \mathrm{Te}\left(\mathrm{t}_{1 / 2}=25 \mathrm{~min}\right)$ which is obtained in nuclear reactor by neutron irradiation of ${ }^{130} \mathrm{Te}$ (Didi et al., 2016). To a lesser extent, ${ }^{131} \mathrm{I}$ is also obtained as a fission product of ${ }^{235} \mathrm{U}$ found in nuclear plants (Khalafi et al., 2005).

Purification of radioiodine from xenon targets is usually performed under a gas stream passed through a furnace heated at $280^{\circ} \mathrm{C}$ containing a silver wire. In these conditions iodine is selectively adsorbed on silver to form Agl, whereas inert Xenon is not retained. On the other hand, isolation of iodine radioisotopes from tellurium targets is accomplished similarly by dry distillation. The target is heated up to the melting point and iodine vapors are transported into an appropriate solution or condensed in a capillary and then dissolved.

In most cases, radioiodine dissolution is performed in a $\mathrm{NaOH}$ solution, which converts the radionuclide into sodium iodide, preventing from the formation of volatile $\mathrm{I}_{2}$ that would occurs at lower $\mathrm{pH}$.

\section{I.I.2 Astatine-211}


Astatine-211 is mainly produced using the ${ }^{209} \mathrm{Bi}(\alpha, 2 \mathrm{n})$ reaction with a medium or high energy cyclotron. The number of cyclotrons having the possibility to accelerate $\alpha$ particles with an energy $>$ $28 \mathrm{MeV}$ being small, this limits ${ }^{211}$ At availability to few centers worldwide (Lindegren et al., 2020). The optimized irradiation conditions are well defined, with the cross section of the nuclear reaction reaching a maximum between 28 and $32 \mathrm{MeV}$ (Lambrecht and Mirzadeh, 1985). During irradiation of bismuth target with alpha particles, other astatine radionuclides are also produced depending on beam energy. Considering its short half-life, ${ }^{212} \mathrm{At}\left(\mathrm{t}_{1 / 2}=0.314 \mathrm{~s}\right)$ does not cause any radionucleidic purity issue. ${ }^{209} \mathrm{At}\left(\mathrm{t}_{1 / 2}=5.41 \mathrm{~h}\right)$ can be easily avoided by limiting the beam energy below $35.9 \mathrm{MeV}$. The production of ${ }^{210} \mathrm{At}\left(\mathrm{t}_{1 / 2}=8.1 \mathrm{~h}\right)$ however, is more problematic due to its unfavourable decay properties, leading by electron capture to the highly toxic alpha emitter ${ }^{210} \mathrm{Po}\left(\mathrm{t}_{1 / 2}=138\right.$ days). Unfortunately, the maximum production energy of ${ }^{211} \mathrm{At}$ also corresponds to the energy threshold $(28.6 \mathrm{MeV})$ of the ${ }^{209} \mathrm{Bi}(\alpha, 3 \mathrm{n})^{210} \mathrm{At}$ reaction. Irradiation conditions must therefore be optimized as a function of acceptable ${ }^{210} \mathrm{At} /{ }^{211} \mathrm{At}$ ratio which is generally considered to be below $10^{-3}$.

Two main strategies are used to process irradiated targets. The wet approach consists in dissolving it in nitric acid, and then extract astatine from dissolved metal salts. This separation may be performed by liquid-liquid extraction, leading to ${ }^{211} \mathrm{At}$ solutions in diisopropylether usable for radiolabeling experiments (Bourgeois et al., 2008) or in $\mathrm{NaOH}$ solution after additional steps (Balkin et al., 2013). Solid phase extraction may also be applied with the advantage of easier automation of the process. Recently studied examples include the use of tellurium column, anion exchange resins or 3-octanone impregnated porous beads to retain astatine during the washing of the solution from impurities followed by elution of pure ${ }^{211}$ At using a specific solvent such as a $\mathrm{NaOH}$ solution (Li et al., 2019; Watanabe et al., 2020) or ethanol (Burns et al., 2021). The second way consists in a dry distillation, similar to iodine radionuclides, for which a heating to $650^{\circ} \mathrm{C}$ is necessary to volatilize ${ }^{211} \mathrm{At}$ and transport it to the recovery solution or tubing using a gas flow (Lindegren et al., 2001). Compared to the wet approach, the dry distillation is potentially more challenging to set up as it involves specific glassware and heating system as well as a delicate gas flow and temperature tuning. It is, however, associated to the undisputable advantage of allowing the recovery of ${ }^{211} \mathrm{At}$ in virtually any solvent that would be necessary for radiolabeling experiments whereas solvent choice is extremely limited via the wet methods.

\section{I.2 Available iodine and astatine species for radiolabeling chemistry}

lodine can exist under several oxidation state $(-\mathrm{I}, 0,+\mathrm{I},+\mathrm{III},+\mathrm{V}$ and $+\mathrm{VIII})$, each exhibiting a specific chemical behavior. In practice, only the $-I$ and the $+\mid$ state are used for radiolabeling. The $-I$ state is the one generally available from commercial suppliers under the sodium iodide form according to the production processes detailed above. $\Gamma^{-}$is nucleophilic and may thus be used as delivered in all nucleophilic mechanisms and in particular aromatic nucleophilic substitutions $\left(\mathrm{S}_{N} \mathrm{Ar}\right)$. It can also be converted into the $+\mid$ oxidation state using a mild oxidizing agent, generally a chloramine or a $\mathrm{N}$ halosuccinimide derivative, to generate electrophilic $\mathrm{I}^{+}$as an interhalogen intermediate $(\mathrm{ICl}$ or $\mathrm{IBr}$ ) to perform electrophilic reactions. Overoxidation due to too strong oxidizers has to be avoided as it would generate volatile species such as $\mathrm{I}_{2}$.

Similarly to iodine, the same oxidation states are expected to be found with astatine. However only the $-I,+I$ and $+I I I$ states have been confirmed with a sufficient degree of confidence to date (Sergentu et al., 2016b). Unlike iodine and lighter halogens, positively charged astatine species exhibit a marked metallic character, which may in principle be used for coordination-based labeling strategy as for radiometals. This has been confirmed with ligands commonly found in radiopharmaceuticals such as EDTA (Ning et al., 1998), and physicochemical studies have identified $\mathrm{At}^{+}$and $\mathrm{AtO}^{+}$as the species involved in these complexes not found with lighter halogens (Champion et al., 2009). However, no 
complexation strong enough for biological application has yet been identified. Consequently, all radiolabeling strategies are similar, if not identical, to radioiodination chemistry, with $\mathrm{At}^{-}$and $\mathrm{At}^{+}$ being also the only species currently in use in radiolabeling chemistry. As initial oxidation state varies from -I to +III depending of the post irradiation process, a redox step is in most case required before use. $\mathrm{At}^{-}$is obtained on a broad $\mathrm{pH}$ range in the presence of a reducing agent such as sulfite or cysteine. $\mathrm{At}^{+}$is generally formed using the same oxidizers as iodine. However, the generation of pure $\mathrm{At}^{+}$is trickier than $\mathrm{At}^{-}$due to its narrow existence domain, and overoxidation to At(III) species is difficult to avoid. This is why a recent trend is the development of reactions using $\mathrm{At}^{-}$rather than $\mathrm{At}^{+}$. It is also important to note that the speciation of At varies over time in solution due to radiolytic degradation of solvents. Radiolysis arises from ${ }^{211}$ At highly energetic alpha decay, forming degradation products (radicals and highly reactive recombination compounds). As radiolysis is correlated to the irradiation dose received by the solution, radiolabeling chemistry with ${ }^{211} A t$ is challenging, especially at high level of activity or when there is a delay between At production and its use (Aneheim et al., 2019; Pozzi and Zalutsky, 2007).

\section{I.3 - Use of radioiodine and astatine without carrier compounds}

lodide being naturally trapped by the thyroid, iodine radioisotopes have found applications without carrier agents, as illustrated by early clinical applications using radioiodide as a radiopharmaceutical for imaging and/or treatment of hyperthyroidism and cancerous nodules (Stokkel et al., 2010). For these applications, the activity is mostly administered orally as gelatin capsules containing radioiodide trapped in a sulfate or hydrogen phosphate salt matrix. Although no clinical applications have been reported, $\left[{ }^{211} \mathrm{At}\right] \mathrm{NaAt}$ is also being investigated on the same principle for treatment of thyroid cancer refractory to classical ${ }^{131}$ I treatment (Liu et al., 2020). Brachytherapy, which consists in implanting seeds containing iodine-125 directly into the tumors, is also an important technique developed mainly for prostate tumors treatment. Implants consist in titanium capsules that contain

${ }^{125}$ I adsorbed on materials (i.e. silver, palladium or ionic resins) coming in different shapes such as spheres, cylinders or wires (Heintz et al., 2001). To prevent capsule degradation and/or activity leakage, continuous efforts are being made to improve the production process of these implants ( $\mathrm{Li}$ et al., 2021).

\section{I.4 - Main reactions for iodine and astatine radiolabeling (Figure 1)}

The choice of a synthetic pathway implies to pay attention to important parameters such as the radionuclide half-life, achievable radiochemical yields (RCY), radiochemical and chemical purity as well as molar activity $\left(A_{m}\right)$ and product homogeneity (regioselectivity) of the final radiohalogenated compound. A rather limited but growing range of labeling methods has been reported so far for radioiodination of organic compounds, they are mainly based on electrophilic or nucleophilic substitutions reactions (Dubost et al., 2020). Due to close chemical properties, astatine chemistry is in many aspect similar to iodine, making radioiodination methods generally applicable to astatination (Guérard et al., 2013), but unexpected differences in reactivity that deviate from the trends observed within the halogen series have also been reported, as discussed in the following sections.

For stability reasons, iodoaryl compounds are preferred to iodoalkyl due to their higher C-I bond energy (respectively 270 and $220 \mathrm{~kJ} / \mathrm{mol}$ ). On the other hand, astatoalkyl compounds are anecdotal due to their too high instability for biological use $\left(C_{\text {alkyl }}-A t=160 \mathrm{~kJ} / \mathrm{mol}\right)$, and only astatoaryl structures $\left(C_{\text {aryl }}-A t=200 \mathrm{~kJ} / \mathrm{mol}\right.$ ) have been used (Coenen et al., 1983).

\section{I.4.1 - Electrophilic approaches}


Halodeprotonation. In conventional synthetic chemistry, aromatic electrophilic substitution $\left(\mathrm{S}_{\mathrm{E}} \mathrm{Ar}\right)$ to generate iodoaryl compounds is a common process. Regioselectivity of substitution reaction is governed by inductive and resonance effects of substituents, the most activating (electron donating) onespromoting ortho and para positions. Examples of radiopharmaceuticals of interest obtained by this approach include the ${ }^{125}$-labeled Omeprazol for stomach imaging (Farrag et al., 2019) whereas direct radioastatination proved less efficient when studying the ${ }^{211} \mathrm{At}$-labeling of methylene blue for melanoma treatment that required elevated temperature $>100^{\circ} \mathrm{C}$ (Norseev, 1998) or in the context of protein labeling (vide infra).

Even if radioiodination reaction is fast, simple to perform and often results in high RCYs and $A_{m}$, polyiodination and formation of positional isomers are non-negligible limits. 
Halodemetallation. The difference in polarity between carbon and metal atoms induces a 
polarization of the carbon-metal bonds, making them more sensitive to electrophilic substitution 
reactions than $\mathrm{C}-\mathrm{H}$ bonds. The higher reactivity of organometallic derivatives makes the substitution 
step more efficient, workable in milder conditions, and applicable to electron deficient aryl 
precursors that would not react in SEAr. Moreover, regioselectivity issues encountered in 
halodeprotonation reactions are overcome since only the metal site will react. Mercury, boron, 
thallium, silicon, germanium and tin have been reported has potential leaving metals for electrophilic 
radioiodination and/or astatination (Coenen et al., 1983; Moerlein et al., 1987). The use of thallium 


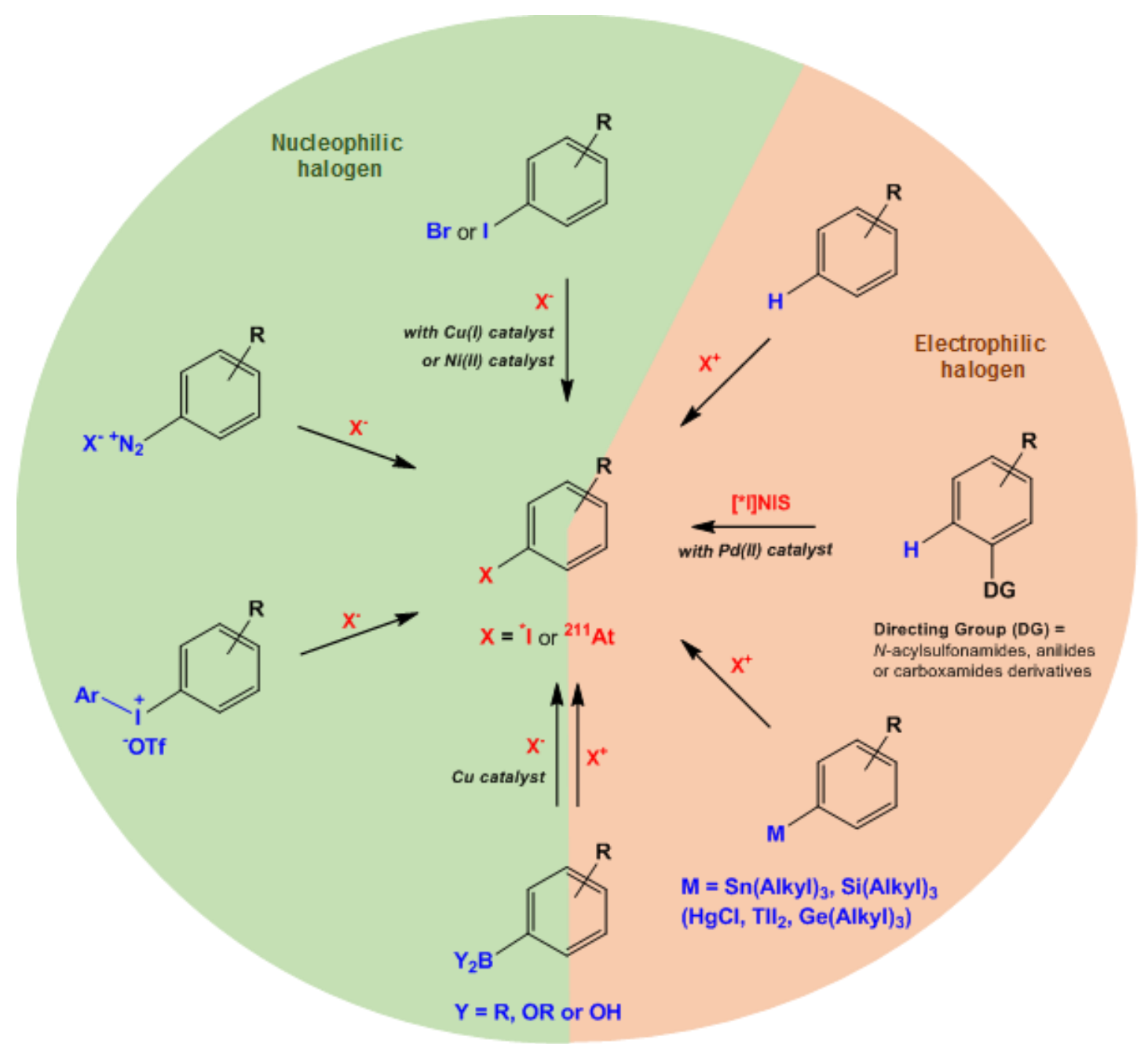

Figure 1. Main approaches for the preparation of radioiodo and astatoaryl compounds, classified as nucleophilic (green) or electrophilic (orange).

and germanium is anecdotal whereas tin has been by far the most used due to its high leaving group 
ability, close to the highly efficient Hg-compounds, but associated to a lower toxicity. The radiolabeling conditions using trialkylaryltin precursors are generally mild, resulting in elevated RCYs and $A_{m} \cdot\left[{ }^{123}\right.$ I] $\beta$-CIT and $\left[{ }^{123}\right.$ I] FP-CIT are two analogues of cocaine produced by iododestannylation that have been approved for detection of Parkinson's disease and are well recognized for their high efficiency (Abbasi Gharibkandi and Hosseinimehr, 2019).

When the alkyl groups on the tin atom were compared, no significant impact on RCYs were reported and the butyl group is generally preferred due to its lower toxicity. The alkyl nature can, however, be modulated with the purpose of improving the purification step. The presence of residual organotin species in the labeled product is a concern for human use and eliminating all traces is essential. Examples of such approaches include the use of fluorine rich alkyl allowing retention of trialkyltin species (substrate and reaction side products) by fluorous solid phase extraction (McIntee et al., 2008), and polymer or ionic liquid supported precursors (Gifford et al., 2011; Rajerison et al., 2016) allowing rapid filtration or extraction, all resulting in time saving procedures and improved RCYs compared to classical HPLC purification systems.

In the group IV metal series, silicon precursors have been used as alternatives to arylstannanes. Their advantages are the lower toxicity and better stability, although their use is limited to electron rich compounds since they are significantly less reactive due to the higher energy of the $\mathrm{C}_{\text {aryl}}$-Si bond $(\approx$ $350 \mathrm{~kJ} / \mathrm{mol}$ vs. $260 \mathrm{~kJ} / \mathrm{mol}$ for $\mathrm{C}_{\text {ary }}-\mathrm{Sn}$ ). Examples of use of this class of precursors are relatively scarce and include the preparation of radioiodinated and astatinated brain probes such as benzylguanidine and phenylalanine (Vaidyanathan et al., 1996; Watanabe et al., 2019). Arylgermanium precursors also appear attractive, being a compromise between tin and silicon precursor with an intermediate $\mathrm{C}_{\text {aryl-Ge }}(310 \mathrm{~kJ} / \mathrm{mol})$ energy and reactivity and with low toxicity. However, only proof of concept studies have been reported for radioiodination (Moerlein, 1985), and these precursors have not yet been used to produce relevant radiopharmaceuticals.

Although the Aryl-B bond energy is higher than in Aryl-Si, deboronation is promoted by the empty $2 p$ orbital of the boron complex that makes possible an electrophilic attack in mild conditions. However, in comparison with the easily accessible arylstannane precursors, arylboron compounds are generally more challenging to prepare. Radioiodination have been reported using arylboronic acids for the preparation of ${ }^{123}$ I-labeled imaging agents such as $\left[{ }^{123} \mathrm{I}\right]$ lodocognex for acetylcholinesterase mapping (Akula et al., 2001) or aminopropyl substituted iodothiophenes for brain imaging (Goodman et al., 1992). Similarly, arylboronate were reported as interesting agents for radioiodination (Kabalka et al., 2002). Arylboron radioiodination chemistry was more recently revisited and improved using either base catalysis (Molloy et al., 2019), or gold catalysis (Webster et al., 2018), providing improved RCYs with otherwise less reactive (electron deficient or sterically hindered) arylboronic acid precursors.

Alternately to the preparation of these above mentioned organometallic precursors, a palladium(II) mediated radioiodination approach under mild conditions was recently developed. The advantage is that the arylpalladium species is generated in situ at a $\mathrm{C}-\mathrm{H}$ position. A specific orienting group is however required in ortho position, limiting the substrate scope (Dubost et al., 2018).

\section{I.4.2 - Nucleophilic approaches}

Isotopic/halogen exchange. This is one of the simplest method for the radioiodination or astatination of organic compounds. An iodine atom present in a molecule of interest can be displaced by an incoming radioiodide or astatide. This reaction often requires high temperature to favor the atom exchange and the use of a copper(I) salt catalyst can ease the exchange reaction. The 
isotopic exchange was mainly investigated for radiolabeling small molecules such as phenylalanine (Meyer et al., 2010; Samnick et al., 2009) or meta-iodobenzylguanidine (MIBG) (Amartey et al., 2001). Also known as lobenguane, MIBG is a tracer that has found applications in imaging or therapy of a broad scope of neuroendrocrine tumors (Vöö et al., 2011). However, in that method, nonradioactive starting material is in large excess in comparison with the radiolabeled product. Both compounds exhibiting identical polarity or nearly identical polarity (for I/At exchange), separation of the radiolabeled product from starting material is not possible, which drastically limits $A_{m}$. For instance, about 1:2000 molecule on average is labeled in standard [ ${ }^{131}$ I]MIBG production, which may reduce treatment efficacy. This is why halodemetallation reaction have also been developed to make non-carrier added MIBG available (Green et al., 2017; Vaidyanathan and Zalutsky, 1993). Alternately, to improve purification efficiency of halogen exchange reactions, the use of the arylbromide analogue as starting material, easier to separate from radiolabeled product, may be considered. Bromide is a poorer leaving group than iodide, but the use of a $\mathrm{Ni}(0)$ catalyst was reported to lead to high RCYs with a broad substrates scope. The approach was applied to the preparation of 5-[23I]A85380, a SPECT tracer of neuronal nicotinic acetylcholine receptors (Cant et al., 2013).

Halodediazotation. Arenediazonium salts are well known precursors in synthetic chemistry for the introduction of nucleophile species, in particular halogenides in the Sandmeyer reaction (Hodgson, 1947). Because diazonium salts exhibit limited stability, they must be generated from the corresponding aniline in situ prior to the substitution step. These precursors were among the first to be studied for radioiodination and astatination, but their use has remained anecdotal because many side products are generated due to competitive reactions induced by the strongly oxidizing and acidic conditions necessary to generate the diazonium intermediate. An improved process was reported that uses milder conditions, the nitrite oxidizing agent being polymer supported, limiting its concentration in solution and lowering detrimental side reactions. The process can be applied efficiently to electron rich and electron deficient aryl compounds and examples of biologically relevant small compounds produced by this approach include the brain imaging agent $\left[{ }^{125}\right.$ I]iomazenil, or $\left[{ }^{125}\right]$ IBOX for amyloid plagues imaging (Sloan et al., 2017).

$S_{N} A r$ with iodonium salts. Hypervalent iodine compounds have emerged as interesting radiohalogenation precursors, especially in the radiofluorination of aryl compounds (Pike, 2018). Likewise, aryliodonium salts are highly efficient to produce radioiodoaryl and astatoaryl compounds. Surprisingly, a significantly higher reactivity of astatide compared to iodide and lighter halogenides was observed (Guérard et al., 2016). One of the main advantages of this approach is the ease of separation of the radiolabeled product from the ionic starting material. Time consuming HPLC purification can easily be replaced by simple extraction or filtration through short chromatographic cartridges, the latter being additionally easily transferable to automated radiosyntheses. Attention has to be paid for the design of precursors in order to favor the regioselectivity of substitution towards the aryl of interest. Regioselectivity is governed by electronic and steric effects and favored when the target compound is an electron poor aryl, and/or when a substituent is present in ortho of the iodonium position. A specific attention must also be paid to the stability of the precursor since potential degradation products include the non-radioactive iodoaryl analogues of final radiolabeled product, having a negative impact on $A_{m}$. The strategy was nonetheless applied successfully to the production of various prosthetic groups for protein radiolabeling (Guérard et al., 2017; Navarro et al., 2019). 
Copper mediated halodeboronation. Arylboron derivatives discussed above as precursors for electrophilic radiohalogenation can also be used in copper catalyzed nucleophilic labeling following a Chan-Evans-Lam like mechanism. Depending on the type of precursor (boronic acid or boronic ester) and the copper salt used, high to quantitative RCYs have been reported, even at room temperature within less than $10 \mathrm{~min}$ (Reilly et al., 2018; Wilson et al., 2016; Zhang et al., 2016). In comparison with electrophilic labeling, the substituents electronic effect appears to have little to no effect on the RCY, whereas steric hindrance in ortho position appears detrimental.

\section{II-Specific approaches for proteins and other large biomolecules labeling}

\section{II.1 Direct radiohalogenation (Figure 2a)}

lodine is the only element with bromine that can react directly with native proteins to produce efficiently and stably labeled radiopharmaceuticals, provided that they contain tyrosine and/or histidine residues as reactive sites for $\mathrm{S}_{\mathrm{E}} \mathrm{Ar}$. The technique was initially developed by Greenwood using Chloramine-T (ChT) as oxidizing agent to generate the ${ }^{*} \mathrm{ICl}$ interhalogen required for the reaction (Greenwood et al., 1963). The addition of a reducing agent such as a sulfite salt is necessary to stop the reaction by neutralizing $\mathrm{ChT}$ and remaining reactive radioiodine before purification. Both oxidizing and reducing conditions may, however, lead to protein alteration, and insoluble versions of this oxidizer are nowadays preferred. IODO-BEADS ${ }^{\circledR}$ is the polystyrene supported analogue of ChT, whereas lodogen ${ }^{\circledast}(1,3,4,6$-tetrachloro-3 $\alpha, 6 \alpha$-diphenylglycouril) is by itself sparingly soluble in water and is used coated on the reaction vial. Since oxidation occurs only at polystyrene or vial wall/solution interface, oxidation is slower. Consequently, radioiodination takes generally longer (up to 30 min compared to less than a minute with $\mathrm{ChT}$ ), but the rate of protein degradation is also drastically reduced (Hermanson, 2013). No reduction step is needed as removing radiolabeling solution from reaction vial stops the reaction. 
Due to its simplicity, this approach has been broadly adopted in biomedical research, the most 
emblematic application being the radioimmunoassay technique. It is also used to produce 
radiopharmaceuticals approved for clinical use, such as ${ }^{131} 1$-Tositumomab (Bexxar ${ }^{\circledR}$ ) for the 
Direct radiohalogenation
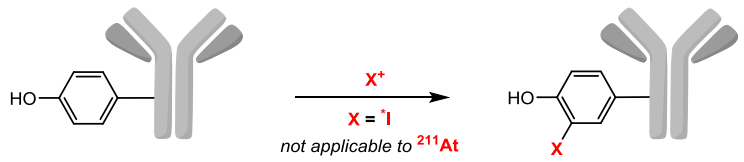

Indirect labelling via the preparation of radiohalogenated prosthetic groups
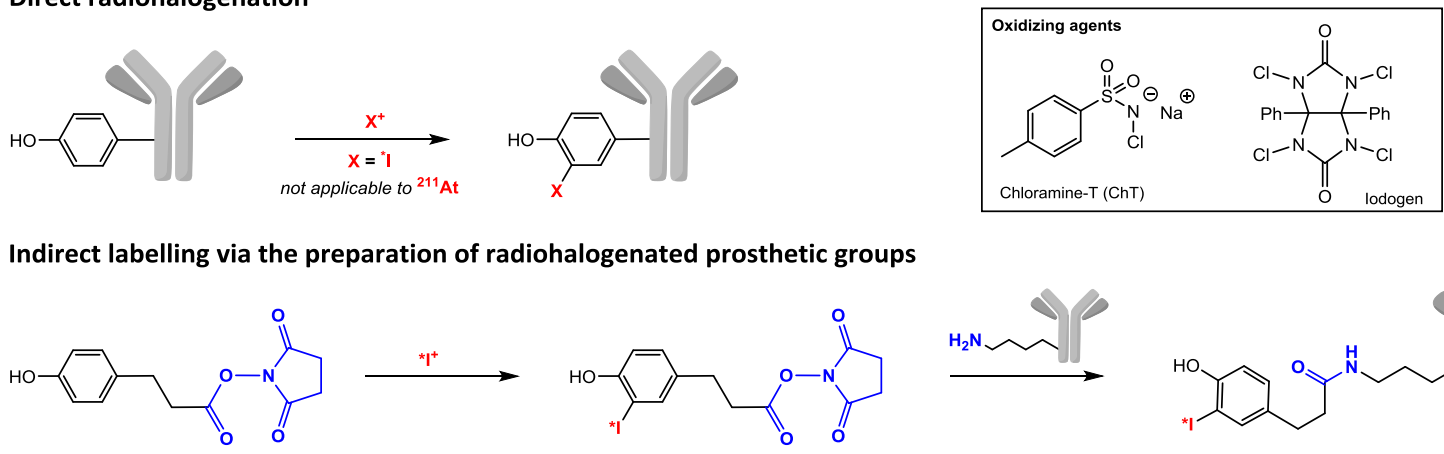

(Bolton-Hunter reagent)

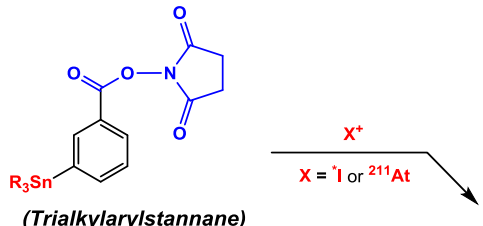

(1)

(Aryliodonium salts)

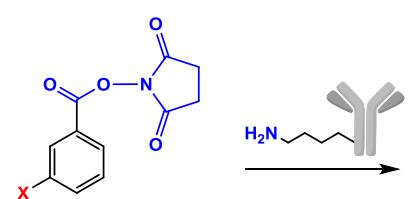

$\left[{ }^{*} I\right] S I B /\left[^{211} A t\right] S A B$

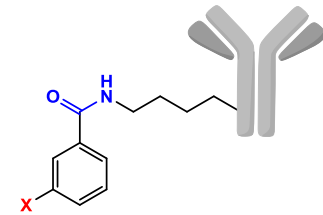

Labelling of pre-modified antibodies
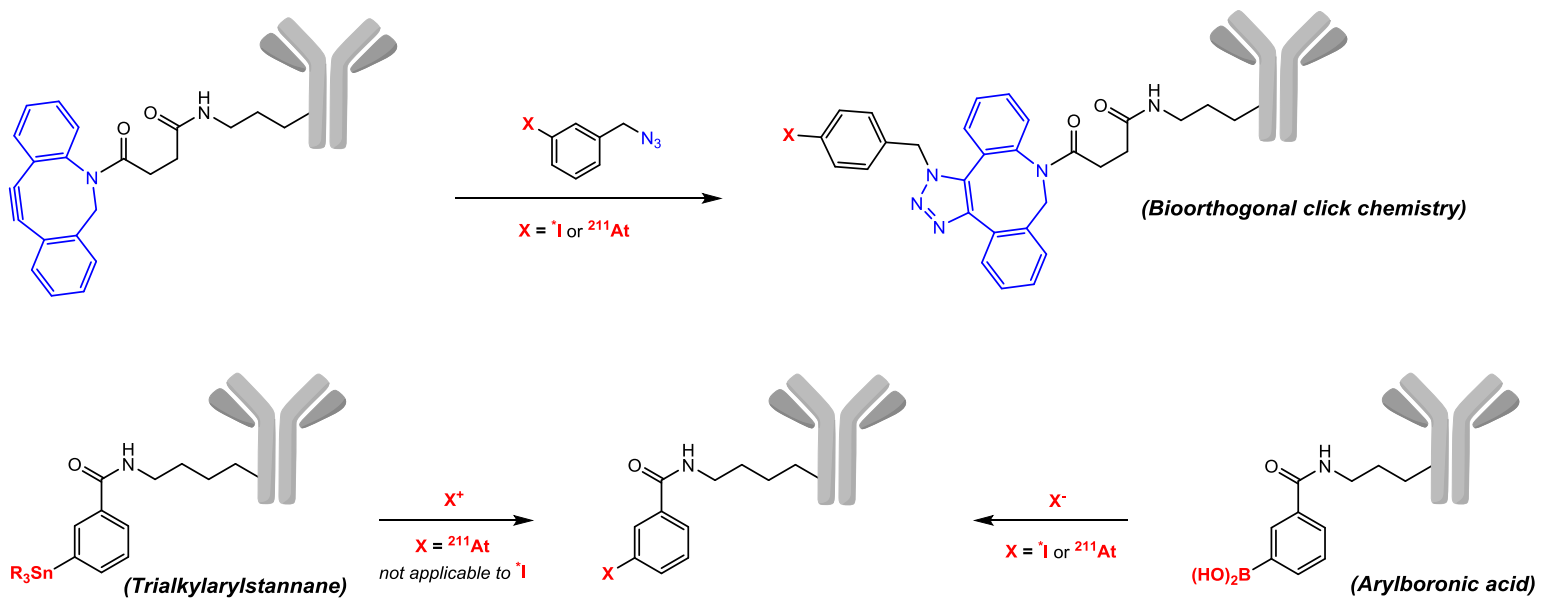

Figure 2. Main strategies for the radioiodination and astatination of proteins.

radioimmunotherapy of Non-Hodgkin's lymphoma (Wahl, 2005). It is, however, not exempt of 
disadvantages. The first one being the necessity of an available tyrosine, which is not always the case, especially for the smallest proteins. Alteration of the protein activity may also be observed when it is too sensitive to the oxidative conditions required, or when iodination occurs at a tyrosine that is involved in target binding. Additionally, because the resulting iodotyrosine pattern is similar to naturally occurring thyroid hormones, dehalogenases lead to a noticeable in vivo instability of the radiolabeling (Cavina et al., 2017).

In the case of astatine, attempts to use this direct approach have failed, the labeling being highly unstable. It was initially thought that the $\mathrm{S}_{\mathrm{E}} A \mathrm{Ar}$ occurs at the tyrosine position, similarly to iodine, with however a much weaker resulting bond (Vaughan and Fremlin, 1978). Further studies indicated that electrophilic astatine cannot react with tyrosine, except if much harsher conditions, incompatible with heat sensitive proteins, were used (Visser et al., 1979). Further investigations indicated a higher stability when these labeling conditions were used on proteins exhibiting free sulfhydryl groups, suggesting that electrophilic astatine bind with sulfur atoms. The resulting bond remains, however, insufficiently stable for in vivo applications (Visser et al., 1981). More recent experimental studies supported by molecular modeling suggest that the electrophilic species involved is not $\mathrm{At}^{+}$, but rather $\mathrm{AtO}^{+}$, and that this species likely forms covalent bonds with sulfur atoms via its oxygen atom (Bassal et al., 2020).

\section{II.2. Indirect labeling via the preparation of radiohalogenated prosthetic groups (Figure $\mathbf{2 b}$ )}

Given the limits of the direct radioiodination and astatination procedures, alternative approaches have been developed consisting in the preparation of a stable radiohalogenated compound that is then exposed to the protein in mild conditions for bioconjugation. The Bolton-Hunter (BH) reagent, which resembles the tyrosine group, is based on a phenolic ring that is activated for bioconjugation via a $\mathrm{N}$-succinmidyl ester (Bolton and Hunter, 1973). It can be electrophilically labeled at the hydroxyl ortho position similarly to tyrosine. It is an interesting strategy when direct tyrosine labeling approach has failed (lack of tyrosine or alteration of protein activity), since it will be conjugated to lysine residues often present in large number, which also lowers the probability of impacting affinity for protein target. However, since it is structurally similar to tyrosine, the same stability issues are observed. Nonetheless, improved enzymatic stability can be reached by removing the hydroxyl group, and alternatives based on the halogenobenzoic acid pattern have emerged. Their preparation is more complex than the $\mathrm{BH}$ reagent since a better leaving group than hydrogen must be introduced in the absence of activating substituent. In most case, the radiolabeling is performed using a trialkylarylstannane precursor providing succinimidyl iodo- or astatobenzoates (SIB or SAB). This approach was reported first with radioiodine (Zalutsky and Narula, 1987) and rapidly applied to astatination with significantly improved in vivo stabilities (Wilbur, 1989; Zalutsky et al., 1989). The position of the halogen (ortho according to Zalustky's compounds or para according to Wilbur) has no impact on the in vivo stability. The use of $\left[{ }^{211} \mathrm{At}\right] \mathrm{SAB}$ has led to a number of preclinical studies and to a clinical trial with a ${ }^{211} \mathrm{At}$-labeled $\mathrm{mAb}$ and continues to be one of the main approach in use (Guérard et al., 2013; Zalutsky et al., 2007). Recent developments have led to a revisit of the methods for producing this prosthetic groups, in particular to improve the ${ }^{211}$ At labeling process. Several drawbacks are indeed related to the use of electrophilic astatodestannylation to produce $\left[{ }^{211} \mathrm{At}\right] \mathrm{SAB}$, and particularly the lack of robustness related to the use of electrophilic At, especially at high activity (see §1.2). Access to SIB and SAB has been in part improved using nucleophilic At and aryliodonium salts as precursors (Guérard et al., 2017) leading to a simplified procedure and

improved RCYs and reproducibility. This approach was used to produce a ${ }^{211} A t-l a b e l e d$ anti-CD138 $\mathrm{mAb}$ in a preclinical therapy study of multiple myeloma (Gouard et al., 2020).

\section{II.3. Labeling of pre-modified antibodies (Figure 2c)}


Impediments of the two-step labeling approaches to straightforward automation and transfer to clinical setting are the suboptimal activity yields induced by the lengths of procedures and loss of activity due to purification of intermediate compounds and vial transfers. Specific activity $\left(A_{s}\right)$ is also limited by the minimum concentration of protein needed at the conjugation step to avoid competitive reaction such as hydrolysis of activated ester in SIB and SAB. In order to improve the critical bioconjugation step, the use of bioorthogonal click chemistry has recently emerged. Whereas the bioconjugation step RCY is in the 50-75\% range using standard acylation prosthetic groups in the most favorable cases, it was possible to reach nearly quantitative RCYs using clickable radiohalogenated prosthetic groups when applied to mAbs preconjugated with the complimentary bioorthogonal handles. Examples are the inverse demand Diels-Alder reaction between a ${ }^{125}$-labeled prosthetic group and a mAb preconjugated with a trans-cyclooctene group, (Albu et al., 2016), or the strain promoted azide alkyne cycloaddition between a ${ }^{211}$ At (or ${ }^{125}$ ) -labeled benzylazide derivative and a mAb preconjugated to a strained cyclooctyne group (Navarro et al., 2019). The mAb concentration needed is lower than when using acylating agents, which should facilitate the improvement of $A_{s}$. Nonetheless, they remain two step-approaches and some of the drawbacks discussed above remain.

To further improve the efficiency of the radiohalogenation procedure, one step approaches in which the radionuclide is directly reacted with a pre-conjugated protein have been developed. The first to be reported is based on organotin chemistry and led to high RCY and $A_{s}$ with reduced procedure time when $\mathrm{N}$-succinimidyl-3-(trimethylstannyl)benzoate was conjugated to trastuzumab and labeled with electrophilic ${ }^{211} \mathrm{At}$. The approach was recently improved using a cysteine coupling approach with an analogous maleimide based precursor to provide a more homogeneous bioconjugation to thiol instead of lysine residues (Aneheim et al., 2016). A faster blood clearance was observed while tumor uptake was preserved compared to the classical $S A B$ based radioimmunoconjugate. This halodemetallation reaction is, however, not applicable to radioiodination since electrophilic iodine would react competitively with tyrosine residues. An alternative that uses the radiohalogens in their nucleophilic form was recently reported. It is based on the bioconjugation of an arylboronic acid that is then labeled in the presence of a copper(II) catalyst (Berdal et al., 2021). The advantages are similar than the method reported by Lindegren, except that it is also applicable to radioiodination without risks of non-specific binding to the protein, nucleophilic iodine being inert with proteins.

\section{Improving the labeling stability}

The C-I bond may be subject to in vivo dissociation, even in aryliodide compounds. The main metabolic pathways leading to deiodination are : i) the action of deiodinase involved in the deiodination of naturally occurring thyroid hormones; ii) oxidative deiodination processes induced by the cytochrome P450 and iii) the action of endogenous nucleophiles able to displace the iodine atom such as thiol containing glutathione. Consequently, specific design must be considered when developing new radioiodinated compounds, such as avoiding patterns similar to iodothyronines and in particular ortho-iodophenol, or attaching electron donating groups rather than electron withdrawing group to the phenyl in order to reduce the action of nucleophiles. Deiodination mechanisms and specific guidelines for the design of stabilized radioiodinated compounds are available in an exhaustive report (Cavina et al., 2017). Interestingly, proteins such as mAbs are in general less prone to deiodination than smaller molecules, due to the lower accessibility of the radioiodinated site to enzymes.

The case of astatinated compounds is significantly more challenging as they are in all cases significantly less stable than their iodinated analogues. Astatine's larger atomic radius and higher polarizability directly impacts the aryl-At bond energy, estimated to be $\approx 197 \mathrm{~kJ} / \mathrm{mol} \mathrm{vs} .268 \mathrm{~kJ} / \mathrm{mol}$ 


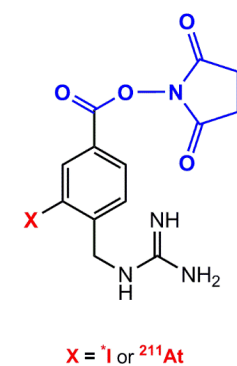

$\left[^{*} I\right] S I G M B /\left[^{211} A t\right] S A G M B$

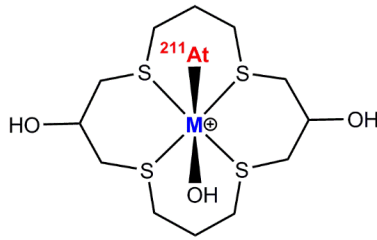

$M=\operatorname{Rh}(I I I)$ or $\operatorname{Ir}(I I I)$

${ }^{211}$ At-M(16-S4-diol) complex

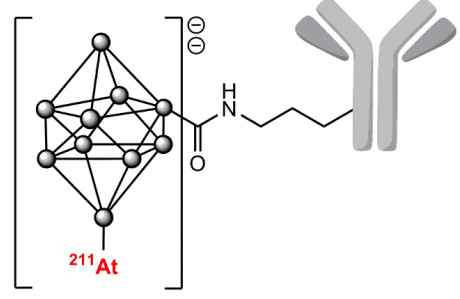

Closo-decaborate(2-) derivative

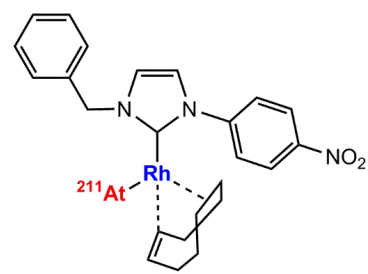

Rhodium NHC astatide complex

Figure 3. Alternative radiolabeling strategies with improved or potentially improved in vivo stability

for the aryl-I bond (Coenen et al., 1983). As a result, activity uptake in thyroid and stomach that are target organs of heavy halogenides is systematically higher for astatinated compounds. Unlike iodine, the instability can also be observed through activity uptake in lungs, kidneys and spleen that are target organs of free astatine. Release of At is particularly observed with small molecules or mAbs internalized within targeted cells (Wilbur, 2008) unlike non-internalized intact mAb that are generally metabolized more slowly. Inspired from observation of radioiodinated compounds, modification of the arylastatide by increasing its electron density have been performed with the aim of strengthening the bond energy (Talanov et al., 2004; Vaidyanathan et al., 1994). The impact on stability seems, however, too low to affect significantly in vivo dissociation. Interestingly, the presence of a positively charged group can limit the release of activity from the cell after the labeled carrier compound has been internalized. Indeed, the addition of a guanidine in [*I]SIGMB and $\left[{ }^{211} A t\right] S A G M B$ prosthetic groups (Figure 3 ) has been used successfully on the internalizing antiEGFRvIII mAb L8A4 (Vaidyanathan et al., 2003, 2001) and more recently on an anti-HER2 nanobody (Dekempeneer et al., 2019). In these cases, the retention of positively charged labeled catabolites is a plausible explanation of the lower activity uptake observed in target tissues of free iodine and astatine.

The mechanisms by which the C-At bond breaks upon internalization within cells are suspected to be in part similar to deiodination, and facilitated by the lower bond energy. In particular, oxidative mechanisms have been pointed out in a report simulating redox and $\mathrm{pH}$ conditions found within the lysosome in cell nucleus (Teze et al., 2017).

In order to limit uptake in a sensitive tissue such as thyroid, or stomach, blocking agents including perchlorate or iodide may be used (Larsen et al., 1998), but research are also directed towards the use of alternatives to the C-At bond. The most advanced strategy is the formation of a B-At bond in boron clusters, and in particular closo-decaborate based prosthetic groups (Figure 3). The bond enthalpy is estimated to be $\approx 50 \%$ higher than the aryl-At bond (Ayed et al., 2016) and translates to a significantly lower release of astatine in vivo when applied to small molecules or larger antibody fragments (Wilbur et al., 2007, 2004). This radiolabeling approach has been used in several successful 
preclinical therapy studies of hematological cancers and lymphoma using mAbs as carrier (Green et al., 2015; O'Steen et al., 2019) as well as in a clinical trial started in 2019 (NCT03128034). A limit of boron clusters is the activity retention in liver and kidney frequently reported, and optimizations are needed in order to apply this approach to a broad scope of carrier molecules, especially when they are smaller than intact mAbs. Another labeling strategy that has shown potential for therapeutic applications consists in the formation of an At-metal bond. The astatide anion being a soft base according to Pearson's classification, a strong affinity for soft cationic metal is expected. Early investigation of complexes formed with mercury confirmed this soft base behavior with the demonstration of a higher stability of complexes of $\mathrm{Hg}$ (II) formed with astatide compared to iodide (Pruszyński et al., 2006). This finding was applied to the formation of bonds with rhodium(III) and iridium(III) themselves trapped within a macrocyclic ligand (Figure 3) (Pruszyński et al., 2008). Despite promising initial results, in vivo studies have not yet proven that these complexes outperform conventional C-At based labeling approaches (Pruszyński et al., 2015). Softer metal cations may provide enhanced stability such as the use of $\mathrm{Rh}(\mathrm{I})$ that exhibited promising labeling stability in human blood serum when complexed to a $N$-heterocyclic carbene ligand (Rajerison et al., 2014).

\section{Future perspectives}

Whereas the optimization of labeling stabilities appears as one of the main challenges to be resolved, especially in the case of astatinated compounds, a general trend in nuclear medicine is the development of radiotheranostic tools in the context of personalized therapy. The concept of radiotheranostic pharmaceuticals is based on the use of a unique compound to perform both imaging and therapy (Jadvar et al., 2018). lodine based theranostic pairs are easily available, ${ }^{123}$ I and ${ }^{124}$ I being complementary to ${ }^{131}$ I. However, ${ }^{211} \mathrm{At}$ is currently the only available isotope of astatine for nuclear medicine applications. The association of radioiodine to ${ }^{211} \mathrm{At}$ is the best option to keep similar pharmacokinetics between both versions of the radiopharmaceutical, as reported with the ${ }^{125}$, and ${ }^{211}$ At-labeled RGD peptide showing similar biodistribution profile in mice (Ogawa et al., 2019). Thus, it appears on the long term essential to develop in close relation both radioiodination and astatination strategies. However, research is also ongoing to make the production of ${ }^{209} \mathrm{At}\left(\mathrm{t}_{1 / 2}=5.4\right.$ h) possible. This $X$-ray and $\gamma$-emitter would forms an ideal theranostic pair with ${ }^{211} A$ t. The possibility to produce this radionuclide has been reported but its use remains currently quite anectodal since it requires a high energy proton beam to generate ${ }^{213} \mathrm{Fr}$, the parent isotope of ${ }^{209} \mathrm{At}$ (Crawford et al., 2017). Nonetheless, the promising SPECT-imaging resolution reported in mice opens perspective for this radionuclide, provided that its availability improves in the future (Crawford et al., 2018).

\section{Conclusion}

The rich chemistry of halogens allows the possibility for radioiodine and astatine to be applied to a broad range of carrier compounds provided that radiolabelling stability is ensured. The broader knowledge on radioiodinated compounds design is mostly due to radioiodine easier accessibility in comparison with astatine and the fact that conventional synthetic chemistry can be used as a model. Research on At labeling chemistry should, however, accelerate with the increase in the number of production sites in the coming years. Moreover, the development of molecular modeling to compensate the absence of spectroscopic tools applicable to this radioelement and investigate new hypothesis will facilitate the development of ${ }^{211}$ At-labeled radiopharmaceuticals (Guo et al., 2018; Sergentu et al., 2016a). This specific research will probably in turn benefit also to the development of new radioiodination strategies.

\section{Acknowledgement}


This work was supported by grants from the French National Agency for Research called "Investissements d'Avenir", Equipex Arronax-Plus (ANR-11-EQPX-0004), Labex IRON (ANR-11LABX-18-01), ISITE NEXT (ANR-16-IDEX-0007) and INCa-DGOS-Inserm_12558.

\section{References}

Abbasi Gharibkandi, N., Hosseinimehr, S.J., 2019. Radiotracers for imaging of Parkinson's disease. European Journal of Medicinal Chemistry 166, 75-89. https://doi.org/10.1016/j.ejmech.2019.01.029

Akula, M.R., Zhang, J.H., Kabalka, G.W., 2001. [123I]lodocognex, a potent spect agent to map acetylcholinesterase via a boronic acid precursor. J Label Compd Radiopharm 44, S260-S261. https://doi.org/10.1002/jlcr.2580440191

Albu, S.A., Al-Karmi, S.A., Vito, A., Dzandzi, J.P.K., Zlitni, A., Beckford-Vera, D., Blacker, M., Janzen, N., Patel, R.M., Capretta, A., Valliant, J.F., 2016. 125I-Tetrazines and Inverse-Electron-Demand Diels-Alder Chemistry: A Convenient Radioiodination Strategy for Biomolecule Labeling, Screening, and Biodistribution Studies. Bioconjugate Chem. 27, 207-216. https://doi.org/10.1021/acs.bioconjchem.5b00609

Amartey, J.K., Al-Jammaz, I., Lambrecht, R.M., 2001. An efficient batch preparation of high specific activity [123I] and [124I] mIBG. Appl Radiat Isot 54, 711-714. https://doi.org/10.1016/S09698043(00)00340-7

Aneheim, E., Gustafsson, A., Albertsson, P., Bäck, T., Jensen, H., Palm, S., Svedhem, S., Lindegren, S., 2016. Synthesis and Evaluation of Astatinated N-[2-(Maleimido)ethyl]-3(trimethylstannyl)benzamide Immunoconjugates. Bioconjugate Chem. 27, 688-697. https://doi.org/10.1021/acs.bioconjchem.5b00664

Aneheim, E., Palm, S., Jensen, H., Ekberg, C., Albertsson, P., Lindegren, S., 2019. Towards elucidating the radiochemistry of astatine - Behavior in chloroform. Sci Rep 9, 1-9. https://doi.org/10.1038/s41598-019-52365-5

Ayed, T., Pilmé, J., Tézé, D., Bassal, F., Barbet, J., Chérel, M., Champion, J., Maurice, R., Montavon, G., Galland, N., 2016. 211At-labeled agents for alpha-immunotherapy: On the in vivo stability of astatine-agent bonds. Eur J Med Chem 116, 156-164. https://doi.org/10.1016/j.ejmech.2016.03.082

Balkin, E.R., Hamlin, D.K., Gagnon, K., Chyan, M.-K., Pal, S., Watanabe, S., Wilbur, D.S., 2013. Evaluation of a Wet Chemistry Method for Isolation of Cyclotron Produced [211At]Astatine. Applied Sciences 3, 636-655. https://doi.org/10.3390/app3030636

Bassal, F., Champion, J., Pardoue, S., Seydou, M., Sabatié-Gogova, A., Deniaud, D., Questel, J.-Y.L., Montavon, G., Galland, N., 2020. Questioning the Affinity of Electrophilic Astatine for Sulfurcontaining Compounds: Unexpected Bindings Revealed. Inorg. Chem. https://doi.org/10.1021/acs.inorgchem.0c01553

Berdal, M., Gouard, S., Eychenne, R., Marionneau-Lambot, S., Croyal, M., Faivre-Chauvet, A., Chérel, M., Gaschet, J., Gestin, J.-F., Guérard, F., 2021. Investigation on the reactivity of nucleophilic radiohalogens with arylboronic acids in water: access to an efficient single-step method for the radioiodination and astatination of antibodies. Chem. Sci. https://doi.org/10.1039/D0SC05191H

Bolton, A.E., Hunter, W.M., 1973. The labelling of proteins to high specific radioactivities by conjugation to a $125 \mathrm{I}$-containing acylating agent. Application to the radioimmunoassay. Biochem J 133, 529-538.

Bourgeois, M., Guérard, F., Alliot, C., Mougin-Degraef, M., Rajerison, H., Remaud-Le Saëc, P., Gestin, J.-F., Davodeau, F., Chérel, M., Barbet, J., Faivre-Chauvet, A., 2008. Feasibility of the radioastatination of a monoclonal antibody with astatine- 211 purified by wet extraction. $J$ Label Compd Radiopharm 51, 379-383. https://doi.org/10.1002/jlcr.1543 
Burns, J.D., Tereshatov, E.E., Avila, G., Glennon, K.J., Hannaman, A., Lofton, K.N., McCann, L.A., McCarthy, M.A., McIntosh, L.A., Schultz, S.J., Tabacaru, G.C., Vonder Haar, A.L., Yennello, S.J., 2021. Rapid recovery of At-211 by extraction chromatography. Separation and Purification Technology 256, 117794. https://doi.org/10.1016/j.seppur.2020.117794

Cant, A.A., Champion, S., Bhalla, R., Pimlott, S.L., Sutherland, A., 2013. Nickel-Mediated Radioiodination of Aryl and Heteroaryl Bromides: Rapid Synthesis of Tracers for SPECT Imaging. Angewandte Chemie International Edition 52, 7829-7832. https://doi.org/10.1002/anie.201302800

Cavina, L., Born, D. van der, Klaren, P.H.M., Feiters, M.C., Boerman, O.C., Rutjes, F.P.J.T., 2017. Design of Radioiodinated Pharmaceuticals: Structural Features Affecting Metabolic Stability towards in Vivo Deiodination. Eur J Med Chem 2017, 3387-3414. https://doi.org/10.1002/ejoc.201601638

Champion, J., Alliot, C., Huclier, S., Deniaud, D., Asfari, Z., Montavon, G., 2009. Determination of stability constants between complexing agents and At(I) and At(III) species present at ultratrace concentrations. Inorg. Chim. Acta 362, 2654-2661. https://doi.org/10.1016/j.ica.2008.12.005

Coenen, H.H., Moerlein, S.M., Stöcklin, G., 1983. No-Carrier Added Radiohalogenation Methods with Heavy Halogens. Radiochim. Acta 34, 47-68.

Crawford, J.R., Kunz, P., Yang, H., Schaffer, P., Ruth, T.J., 2017. 211Rn/211At and 209At production with intense mass separated Fr ion beams for preclinical 211At-based $\alpha$-therapy research. Appl Radiat Isot 122, 222-228. https://doi.org/10.1016/j.apradiso.2017.01.035

Crawford, J.R., Robertson, A.K.H., Yang, H., Rodríguez-Rodríguez, C., Esquinas, P.L., Kunz, P., Blinder, S., Sossi, V., P Schaffer, Ruth, T.J., 2018. Evaluation of 209 At as a theranostic isotope for 209 At-radiopharmaceutical development using high-energy SPECT. Phys. Med. Biol. 63, 045025. https://doi.org/10.1088/1361-6560/aaaa95

Dekempeneer, Y., Bäck, T., Aneheim, E., Jensen, H., Puttemans, J., Xavier, C., Keyaerts, M., Palm, S., Albertsson, P., Lahoutte, T., Caveliers, V., Lindegren, S., D'Huyvetter, M., 2019. Labeling of Anti-HER2 Nanobodies with Astatine-211: Optimization and the Effect of Different Coupling Reagents on Their in Vivo Behavior. Mol. Pharmaceutics 16, 3524-3533. https://doi.org/10.1021/acs.molpharmaceut.9b00354

Didi, A., Dadouch, A., Bekkouri, H.E., 2016. Feasibility study for production of iodine-131 using dioxide of tellurium-130. Int J Pharm Pharm Sci 327-331. https://doi.org/10.22159/ijpps.2016v8i11.13595

Dubost, E., Babin, V., Benoist, F., Hébert, A., Barbey, P., Chollet, C., Bouillon, J.-P., Manrique, A., Pieters, G., Fabis, F., Cailly, T., 2018. Palladium-Mediated Site-Selective C-H Radio-iodination. Org. Lett. 20, 6302-6305. https://doi.org/10.1021/acs.orglett.8b02819

Dubost, E., McErlain, H., Babin, V., Sutherland, A., Cailly, T., 2020. Recent Advances in Synthetic Methods for Radioiodination. J. Org. Chem. https://doi.org/10.1021/acs.joc.0c00644

Farrag, N.S., Abdel-Halim, H.A., Moamen, O.A.A., 2019. Facile radiolabeling optimization process via design of experiments and an intelligent optimization algorithm: Application for omeprazole radioiodination. J Label Compd Radiopharm 62, 280-287. https://doi.org/10.1002/jlcr.3734

Firouzbakht, M.L., Teng, R.-R., Schlyer, D.J., Wolf, A.P., 1987. Production of High Purity lodine-123 from Xenon-124 at Energies Between 15 and 34 MeV. Radiochim Acta 41, 1-4. https://doi.org/10.1524/ract.1987.41.1.1

Gifford, A.N., Kuschel, S., Shea, C., Fowler, J.S., 2011. Polymer-Supported Organotin Reagent for Prosthetic Group Labeling of Biological Macromolecules with Radioiodine. Bioconjugate Chem. 22, 406-412. https://doi.org/10.1021/bc1004203

Goodman, M.M., Kabalka, G.W., Marks, R.C., Knapp, F.F., Lee, J., Liang, Y., 1992. Synthesis and evaluation of radioiodinated 2-(2(RS)-aminopropyl)-5-iodothiophenes as brain imaging agents. J. Med. Chem. 35, 280-285. https://doi.org/10.1021/jm00080a012

Gouard, S., Maurel, C., Marionneau-Lambot, S., Dansette, D., Bailly, C., Guérard, F., Chouin, N., Haddad, F., Alliot, C., Gaschet, J., Eychenne, R., Kraeber-Bodéré, F., Chérel, M., 2020. 
Targeted-Alpha-Therapy Combining Astatine-211 and anti-CD138 Antibody in a Preclinical Syngeneic Mouse Model of Multiple Myeloma Minimal Residual Disease. Cancers 12, 2721. https://doi.org/10.3390/cancers12092721

Green, D.J., Shadman, M., Jones, J.C., Frayo, S.L., Kenoyer, A.L., Hylarides, M.D., Hamlin, D.K., Wilbur, D.S., Balkan, E.R., Lin, Y., Miller, B.W., Frost, S.H.L., Gopal, A.K., Orozco, J.J., Gooley, T.A., Laird, K.L., Till, B.G., Bäck, T., Sandmaier, B.M., Pagel, J.M., Press, O.W., 2015. Astatine-211 conjugated to an anti-CD20 monoclonal antibody eradicates disseminated B-cell lymphoma in a mouse model. Blood 125, 2111-2119. https://doi.org/10.1182/blood-2014-11-612770

Green, M., Lowe, J., Kadirvel, M., McMahon, A., Westwood, N., Chua, S., Brown, G., 2017. Radiosynthesis of no-carrier-added meta-[124I]iodobenzylguanidine for PET imaging of metastatic neuroblastoma. J Radioanal Nucl Chem 311, 727-732. https://doi.org/10.1007/s10967-016-5073-1

Greenwood, F., Hunter, W., Glover, J., 1963. The preparation of 131l-labelled human growth hormone of high specific radioactivity. Biochem J 89, 114-123. https://doi.org/10.1042/bj0890114

Guérard, F., Gestin, J.-F., Brechbiel, M.W., 2013. Production of [211At]-Astatinated Radiopharmaceuticals and Applications in Targeted $\alpha$-Particle Therapy. Cancer Biother Radiopharm 28, 1-20. https://doi.org/10.1089/cbr.2012.1292

Guérard, F., Lee, Y.-S., Baidoo, K., Gestin, J.-F., Brechbiel, M.W., 2016. Unexpected Behavior of the Heaviest Halogen Astatine in the Nucleophilic Substitution of Aryliodonium Salts. Chem. Eur. J. 22, 12332-12339. https://doi.org/10.1002/chem.201600922

Guérard, F., Navarro, L., Lee, Y.-S., Roumesy, A., Alliot, C., Chérel, M., Brechbiel, M.W., Gestin, J.-F., 2017. Bifunctional aryliodonium salts for highly efficient radioiodination and astatination of antibodies. Bioorg Med Chem 25, 5975-5980. https://doi.org/10.1016/j.bmc.2017.09.022

Guo, N., Maurice, R., Teze, D., Graton, J., Champion, J., Montavon, G., Galland, N., 2018. Experimental and computational evidence of halogen bonds involving astatine. Nat. Chem. 10, 428-434. https://doi.org/10.1038/s41557-018-0011-1

Heintz, B.H., Wallace, R.E., Hevezi, J.M., 2001. Comparison of I-125 sources used for permanent interstitial implants. Medical Physics 28, 671-682. https://doi.org/10.1118/1.1359246

Hermanson, G.T., 2013. Chapter 12 - Isotopic Labeling Techniques, in: Hermanson, G.T. (Ed.), Bioconjugate Techniques (Third Edition). Academic Press, Boston, pp. 507-534. https://doi.org/10.1016/B978-0-12-382239-0.00012-1

Hodgson, H.H., 1947. The Sandmeyer Reaction. Chem. Rev. 40, 251-277. https://doi.org/10.1021/cr60126a003

Jadvar, H., Chen, X., Cai, W., Mahmood, U., 2018. Radiotheranostics in Cancer Diagnosis and Management. Radiology 286, 388-400. https://doi.org/10.1148/radiol.2017170346

Kabalka, G.W., Akula, M.R., Zhang, J., 2002. Synthesis of radioiodinated aryl iodides via boronate precursors. Nucl Med Biol 29, 841-843. https://doi.org/10.1016/S0969-8051(02)00344-X

Khalafi, H., Nazari, K., Ghannadi-Maragheh, M., 2005. Investigation of efficient 131I production from natural uranium at Tehran research reactor. Annals of Nuclear Energy 32, 729-740. https://doi.org/10.1016/j.anucene.2004.12.008

Lambrecht, R.M., Mirzadeh, S., 1985. Cyclotron isotopes and radiopharmaceuticals-XXXV astatine211. Int J Appl Radiat Isot 36, 443-450. https://doi.org/10.1016/0020-708X(85)90207-8

Larsen, R.H., Slade, S., Zalutsky, M.R., 1998. Blocking [211At]astatide accumulation in normal tissues: preliminary evaluation of seven potential compounds. Nucl. Med. Biol. 25, 351-357.

Li, Y., Hamlin, D.K., Chyan, M.-K., Morscheck, T.M., Ferrier, M.G., Wong, R., Wilbur, D.S., 2019. Investigation of a tellurium-packed column for isolation of astatine-211 from irradiated bismuth targets and demonstration of a semi-automated system. Sci Rep 9, 1-7. https://doi.org/10.1038/s41598-019-53385-x

Li, Z.-Y., Gao, H.-B., Zhang, W.-H., Zhang, X.-F., Han, L.-G., Cui, H.-P., 2021. Preparation of 125 I brachytherapy seeds by iodinating carbon bars with a silver coating. Applied Radiation and Isotopes 167, 109426. https://doi.org/10.1016/j.apradiso.2020.109426 
Lindegren, S., Albertsson, P., Bäck, T., Jensen, H., Palm, S., Aneheim, E., 2020. Realizing Clinical Trials with Astatine-211: The Chemistry Infrastructure. Cancer Biother Radiopharm 35, 425-436. https://doi.org/10.1089/cbr.2019.3055

Lindegren, S., Bäck, T., Jensen, H.J., 2001. Dry-distillation of astatine-211 from irradiated bismuth targets: a time-saving procedure with high recovery yields. Appl. Radiat. Isot. 55, 157-160.

Liu, Y., Watabe, T., Kaneda-Nakashima, K., Ooe, K., Shirakami, Y., Toyoshima, A., Shimosegawa, E., Nakano, T., Shinohara, A., Hatazawa, J., 2020. Preclinical Evaluation of Radiation-Induced Toxicity in Targeted Alpha Therapy Using [211At] NaAt in Mice: A Revisit. Translational Oncology 13, 100757. https://doi.org/10.1016/j.tranon.2020.100757

Mahunka, I., Andó, L., Mikecz, P., Tcheltsov, A.N., Suvorov, I.A., 1996. lodine-123 production at a small cyclotron for medical use. J Radioanal Nucl Chem Lett 213, 135-142. https://doi.org/10.1007/BF02165245

Martinho, E., Neves, M.A., Freita, M.C., 1984. 125I production: Neutron irradiation planning. Int J Appl Radiat Isot 35, 933-938. https://doi.org/10.1016/0020-708X(84)90205-9

McIntee, J.W., Sundararajan, C., Donovan, A.C., Kovacs, M.S., Capretta, A., Valliant, J.F., 2008. A Convenient Method for the Preparation of Fluorous Tin Derivatives for the Fluorous Labeling Strategy. J. Org. Chem. 73, 8236-8243. https://doi.org/10.1021/jo8013287

Meyer, G.J., Walte, A., Sriyapureddy, S.R., Grote, M., Krull, D., Korkmaz, Z., Knapp, W.H., 2010. Synthesis and analysis of 2-[211At]-I-phenylalanine and 4-[211At]-I-phenylalanine and their uptake in human glioma cell cultures in-vitro. Appl. Radiat. Isot. 68, 1060-1065. https://doi.org/10.1016/j.apradiso.2009.12.043

Moerlein, S.M., 1985. Regiospecific incorporation of no-carrier-added radiobromine and radioiodine into aromatic rings via halogenodegermylation. J. Chem. Soc., Perkin Trans. 1 1687-1692. https://doi.org/10.1039/P19850001687

Moerlein, S.M., Mathis, C.A., Yano, Y., 1987. Comparative evaluation of electrophilic aromatic iododemetallation techniques for labeling radiopharmaceuticals with iodine-122. Appl Radiat Isot 38, 85-90. https://doi.org/10.1016/0883-2889(87)90001-3

Molloy, J.J., O'Rourke, K.M., Frias, C.P., Sloan, N.L., West, M.J., Pimlott, S.L., Sutherland, A., Watson, A.J.B., 2019. Mechanism of Cu-Catalyzed Aryl Boronic Acid Halodeboronation Using Electrophilic Halogen: Development of a Base-Catalyzed lododeboronation for Radiolabeling Applications. Org. Lett. 21, 2488-2492. https://doi.org/10.1021/acs.orglett.9b00942

Navarro, L., Berdal, M., Chérel, M., Pecorari, F., Gestin, J.-F., Guérard, F., 2019. Prosthetic groups for radioiodination and astatination of peptides and proteins: $A$ comparative study of five potential bioorthogonal labeling strategies. Bioorg. Med. Chem. 27, 167-174. https://doi.org/10.1016/j.bmc.2018.11.034

Ning, L., Jiannan, J., Shangwu, M., Hengliu, C., Yanping, Y., 1998. Preparation and premilinary evaluation of astatine-211 labeled IgG via DTPA anhydride. J. Rad. Nucl. Chem. 227, 187-190. https://doi.org/10.1007/BF02386459

Norseev, Yu., 1998. Synthesis of astatine-tagged methylene blue, a compound for fighting micrometastases and individual cells of melanoma. J. Rad. Nucl. Chem. 237, 155-158. https://doi.org/10.1007/BF02386681

Ogawa, K., Takeda, T., Mishiro, K., Toyoshima, A., Shiba, K., Yoshimura, T., Shinohara, A., Kinuya, S., Odani, A., 2019. Radiotheranostics Coupled between an At-211-Labeled RGD Peptide and the Corresponding Radioiodine-Labeled RGD Peptide. ACS Omega 4, 4584-4591. https://doi.org/10.1021/acsomega.8b03679

O’Steen, S., Comstock, M.L., Orozco, J.J., Hamlin, D.K., Wilbur, D.S., Jones, J.C., Kenoyer, A., Nartea, M.E., Lin, Y., Miller, B.W., Gooley, T.A., Tuazon, S.A., Till, B.G., Gopal, A.K., Sandmaier, B.M., Press, O.W., Green, D.J., 2019. The $\alpha$-emitter astatine-211 targeted to CD38 can eradicate multiple myeloma in a disseminated disease model. Blood 134, 1247-1256. https://doi.org/10.1182/blood.2019001250

Pike, V.W., 2018. Hypervalent aryliodine compounds as precursors for radiofluorination. J Label Compd Radiopharm 61, 196-227. https://doi.org/10.1002/jlcr.3570 
Pozzi, O.R., Zalutsky, M.R., 2007. Radiopharmaceutical chemistry of targeted radiotherapeutics, Part 3: alpha-particle-induced radiolytic effects on the chemical behavior of (211)At. J. Nucl. Med. 48, 1190-1196. https://doi.org/10.2967/jnumed.106.038505

Pruszyński, M., Bilewicz, A., Wąs, B., Petelenz, B., 2006. Formation and stability of astatide-mercury complexes. J. Rad. Nucl. Chem. 268, 91-94. https://doi.org/10.1007/s10967-006-0129-2

Pruszyński, M., Bilewicz, A., Zalutsky, M.R., 2008. Preparation of Rh[16aneS4-diol]211At and Ir[16aneS4-diol]211At Complexes as Potential Precursors for Astatine Radiopharmaceuticals. Part I: Synthesis. Bioconjugate Chem. 19, 958-965. https://doi.org/10.1021/bc700413r

Pruszyński, M., Łyczko, M., Bilewicz, A., Zalutsky, M.R., 2015. Stability and in vivo behavior of $\mathrm{Rh}$ [16aneS4-diol]211At complex: A potential precursor for astatine radiopharmaceuticals. Nucl Med Biol 42, 439-445. https://doi.org/10.1016/j.nucmedbio.2014.12.011

Qaim, S.M., Hohn, A., Bastian, T., El-Azoney, K.M., Blessing, G., Spellerberg, S., Scholten, B., Coenen, H.H., 2003. Some optimisation studies relevant to the production of high-purity $124 \mathrm{I}$ and $120 \mathrm{gl}$ at a small-sized cyclotron. Appl Radiat Isot 58, 69-78. https://doi.org/10.1016/S09698043(02)00226-9

Rajerison, H., Faye, D., Roumesy, A., Louaisil, N., Boeda, F., Faivre-Chauvet, A., Gestin, J.-F., Legoupy, S., 2016. Ionic liquid supported organotin reagents to prepare molecular imaging and therapy agents. Org. Biomol. Chem. 14, 2121-2126. https://doi.org/10.1039/C5OB02459E

Rajerison, H., Guérard, F., Mougin-Degraef, M., Bourgeois, M., Da Silva, I., Chérel, M., Barbet, J., Faivre-Chauvet, A., Gestin, J.-F., 2014. Radioiodinated and astatinated NHC rhodium complexes: Synthesis. Nucl Med Biol 41, Supplement, e23-e29. https://doi.org/10.1016/j.nucmedbio.2013.12.004

Reilly, S.W., Makvandi, M., Xu, K., Mach, R.H., 2018. Rapid Cu-Catalyzed [211At]Astatination and [125I]lodination of Boronic Esters at Room Temperature. Org. Lett. 20, 1752-1755. https://doi.org/10.1021/acs.orglett.8b00232

Samnick, S., Romeike, B.F., Lehmann, T., Israel, I., Rübe, C., Mautes, A., Reiners, C., Kirsch, C.-M., 2009. Efficacy of Systemic Radionuclide Therapy with p-131I-lodo-I-Phenylalanine Combined with External Beam Photon Irradiation in Treating Malignant Gliomas. J Nucl Med 50, 20252032. https://doi.org/10.2967/jnumed.109.066548

Sergentu, D.-C., David, G., Montavon, G., Maurice, R., Galland, N., 2016a. Scrutinizing "Invisible" astatine: A challenge for modern density functionals. J. Comput. Chem. 37, 1345-1354. https://doi.org/10.1002/jcc.24326

Sergentu, D.-C., Teze, D., Sabatié-Gogova, A., Alliot, C., Guo, N., Bassal, F., Silva, I.D., Deniaud, D., Maurice, R., Champion, J., Galland, N., Montavon, G., 2016b. Advances on the Determination of the Astatine Pourbaix Diagram: Predomination of AtO $(\mathrm{OH}) 2$ - over At- in Basic Conditions. Chem. Eur. J. 22, 2964-2971. https://doi.org/10.1002/chem.201504403

Sloan, N.L., Luthra, S.K., McRobbie, G., Pimlott, S.L., Sutherland, A., 2017. A one-pot radioiodination of aryl amines via stable diazonium salts: preparation of 1251-imaging agents. Chem. Commun. 53, 11008-11011. https://doi.org/10.1039/C7CC06211G

Stokkel, M.P.M., Handkiewicz Junak, D., Lassmann, M., Dietlein, M., Luster, M., 2010. EANM procedure guidelines for therapy of benign thyroid disease. Eur I Nucl Med Mol Imaging 37, 2218-2228. https://doi.org/10.1007/s00259-010-1536-8

Talanov, V.S., Yordanov, A.T., Garmestani, K., Milenic, D.E., Arora, H.C., Plascjak, P.S., Eckelman, W.C., Waldmann, T.A., Brechbiel, M.W., 2004. Preparation and in vivo evaluation of novel linkers for 211At labeling of proteins. Nucl. Med. Biol. 31, 1061-1071. https://doi.org/10.1016/j.nucmedbio.2004.08.005

Teze, D., Sergentu, D.-C., Kalichuk, V., Barbet, J., Deniaud, D., Galland, N., Maurice, R., Montavon, G., 2017. Targeted radionuclide therapy with astatine-211: Oxidative dehalogenation of astatobenzoate conjugates. Sci. Rep. 7, 2579. https://doi.org/10.1038/s41598-017-02614-2

Vaidyanathan, G., Affleck, D., Zalutsky, M.R., 1994. Monoclonal antibody F(ab')2 fragment labeled with $\mathrm{N}$-succinimidyl 2,4-dimethoxy-3-halobenzoates: in vivo comparison of iodinated and astatinated fragments. Nucl. Med. Biol 21, 105-110. 
Vaidyanathan, G., Affleck, D.J., Bigner, D.D., Zalutsky, M.R., 2003. N-succinimidyl 3-[211At]astato-4guanidinomethylbenzoate: an acylation agent for labeling internalizing antibodies with alphaparticle emitting 211At. Nucl. Med. Biol. 30, 351-359.

Vaidyanathan, G., Affleck, D.J., Li, J., Welsh, P., Zalutsky, M.R., 2001. A Polar Substituent-Containing Acylation Agent for the Radioiodination of Internalizing Monoclonal Antibodies: NSuccinimidyl 4-Guanidinomethyl-3-[131I]iodobenzoate ([131I]SGMIB). Bioconjugate Chem 12, 428-438. https://doi.org/10.1021/bc0001490

Vaidyanathan, G., Affleck, D.J., Zalutsky, M.R., 1996. No-Carrier-Added (4-Fluoro-3[131I]iodobenzyl)guanidine and (3-[211At]Astato-4-fluorobenzyl)guanidine. Bioconjugate Chem 7, 102-107. https://doi.org/10.1021/bc950078i

Vaidyanathan, G., Zalutsky, M.R., 1993. No-carrier-added synthesis of meta[1311]iodobenzylguanidine. Applied Radiation and Isotopes 44, 621-628. https://doi.org/10.1016/0969-8043(93)90179-E

Vaughan, A.T., Fremlin, J.H., 1978. The preparation of astatine labelled proteins using an electrophilic reaction. Int. J. Nucl. Med. Biol. 5, 229-230.

Visser, G.W.M., Diemer, E.L., Kaspersen, F.M., 1981. The nature of the astatine-protein bond. Int. J. Appl Radiat. Isot. 32, 905-912. https://doi.org/10.1016/0020-708X(81)90077-6

Visser, G.W.M., Diemer, E.L., Kaspersen, F.M., 1979. The preparation and stability of astatotyrosine and astato-iodotyrosine. Int. J. Appl Radiat. Isot. 30, 749-752. https://doi.org/10.1016/0020708X(79)90154-6

Vöö, S., Bucerius, J., Mottaghy, F.M., 2011. I-131-MIBG therapies. Methods, Nuclear Molecular Therapies 55, 238-245. https://doi.org/10.1016/j.ymeth.2011.10.006

Wahl, R.L., 2005. Tositumomab and 131I Therapy in Non-Hodgkin's Lymphoma. J Nucl Med 46, 128S$140 \mathrm{~S}$.

Watanabe, S., Azim, M.A.-U., Nishinaka, I., Sasaki, I., Ohshima, Y., Yamada, K., Ishioka, N.S., 2019. A convenient and reproducible method for the synthesis of astatinated 4-[211At]astato-Lphenylalanine via electrophilic desilylation. Org. Biomol. Chem. 17, 165-171. https://doi.org/10.1039/С8OB02394H

Watanabe, Shigeki, Sasaki, I., Watanabe, Satoshi, Higashi, T., Ishioka, N.S., 2020. A simple isolation of 211At using an anion-exchange spin column method. J Radioanal Nucl Chem. https://doi.org/10.1007/s10967-020-07422-z

Webster, S., O'Rourke, K.M., Fletcher, C., Pimlott, S.L., Sutherland, A., Lee, A.-L., 2018. Rapid lododeboronation with and without Gold Catalysis: Application to Radiolabelling of Arenes. Chem Eur J 24, 937-943. https://doi.org/10.1002/chem.201704534

Wilbur, D.S., 2008. [211At]Astatine-Labeled Compound Stability: Issues with Released [211At]Astatide and Development of Labeling Reagents to Increase Stability. Current Radiopharm. 1, 144-176. https://doi.org/10.2174/1874471010801030144

Wilbur, D.S., 1989. Reaction of organometallic compounds with astatine-211. Application to protein labeling. Radiochim Acta 47, 137-142.

Wilbur, D.S., Chyan, M.-K., Hamlin, D.K., Vessella, R.L., Wedge, T.J., Hawthorne, M.F., 2007. Reagents for astatination of biomolecules. 2. Conjugation of anionic boron cage pendant groups to a protein provides a method for direct labeling that is stable to in vivo deastatination. Bioconjugate Chem. 18, 1226-1240. https://doi.org/10.1021/bc060345s

Wilbur, D.S., Zalutsky, M., Wedge, T.J., Hawthorne, M.F., Chyan, M.-K., Hamlin, D.K., Kegley, B.B., Risler, R., Pathare, P.M., Quinn, J., Vessella, R.L., Foulon, C., 2004. Reagents for astatination of biomolecules: comparison of the in vivo distribution and stability of some radioiodinated/astatinated benzamidyl and nido-carboranyl compounds. Bioconjugate Chem. 15, 203-223. https://doi.org/10.1021/bc034175k

Wilson, T.C., McSweeney, G., Preshlock, S., Verhoog, S., Tredwell, M., Cailly, T., Gouverneur, V., 2016. Radiosynthesis of SPECT tracers via a copper mediated 123I iodination of (hetero)aryl boron reagents. Chem. Commun. 52, 13277-13280. https://doi.org/10.1039/C6CC07417K 
Zalutsky, M.R., Garg, P.K., Friedman, H.S., Bigner, D.D., 1989. Labeling monoclonal antibodies and $F\left(a b^{\prime}\right) 2$ fragments with the alpha-particle-emitting nuclide astatine-211: preservation of immunoreactivity and in vivo localizing capacity. Proc. Natl. Acad. Sci. U.S.A 86, 7149-7153. https://doi.org/10.1073/pnas.86.18.7149

Zalutsky, M.R., Narula, A.S., 1987. A method for the radiohalogenation of proteins resulting in decreased thyroid uptake of radioiodine. Appl. Radiat. Isot. 38, 1051-1055. https://doi.org/10.1016/0883-2889(87)90069-4

Zalutsky, M.R., Reardon, D.A., Pozzi, O.R., Vaidyanathan, G., Bigner, D.D., 2007. Targeted alphaparticle radiotherapy with 211At-labeled monoclonal antibodies. Nucl. Med. Biol 34, 779785. https://doi.org/10.1016/j.nucmedbio.2007.03.007

Zhang, P., Zhuang, R., Guo, Z., Su, X., Chen, X., Zhang, X., 2016. A Highly Efficient Copper-Mediated Radioiodination Approach Using Aryl Boronic Acids. Chem. Eur. J. 22, 16783-16786. https://doi.org/10.1002/chem.201604105 